Patel urged to drop

plans for inaccurate, unethical dental checks

\section{on migrants}

The British Dental Association has urged Home Secretary Priti Patel to think again on plans to introduce dental checks to establish the age of Channel migrants.

According to reports, a new independent nationwide panel will use dental records and other 'scientific evidence' to verify the age of asylum seekers. The Association has vigorously opposed the use of dental X-rays to determine whether asylum seekers have reached the age of 18 , stressing they are an inaccurate method for assessing age.

The BDA also believes that it is inappropriate and unethical to take radiographs of people when there is no health benefit for them. X-rays taken for a clinically justified reason must not be used for another purpose without the patient's informed consent and must be carried out without coercion and in full knowledge of how the radiograph will be used and by whom.

The new Nationality and Borders Bill, tabled yesterday, will give the Home Secretary the powers to introduce methods of assessing age via regulation.

This new position runs counter to statements adopted by the Home Office in 2016, when the Department rejected similar calls from backbencher David Davies MP.

BDA Chair Eddie Crouch said: 'This is a retrograde step from Priti Patel.

'In 2016 the Home Office ruled out dental checks for migrants, which we considered inaccurate, inappropriate and unethical.

'In 2021 the science and ethics have not changed.'

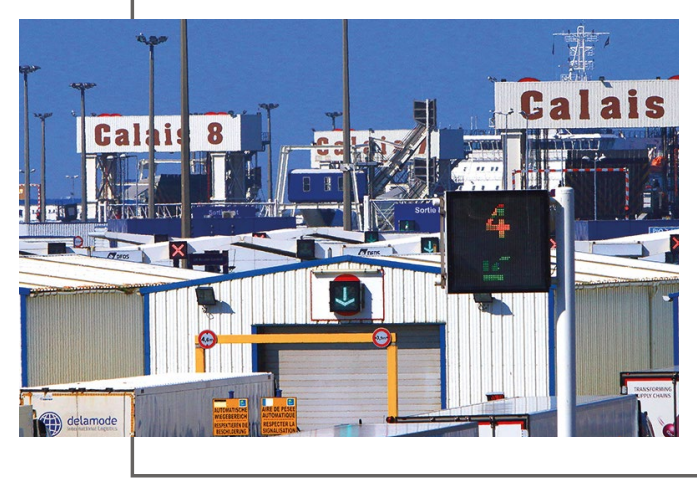

\title{
GDC announces new chair
}

Baron Harris of Haringey will join the GDC as Chair of Council, and

Angie Heilmann MBE, who joins as a registrant Council Member.

Both will take up their new posts on 1 October 2021, when the current Chair Dr William Moyes and Council Member Catherine Brady leave office at the end of September.

Lord Toby Harris currently chairs the National Preparedness Commission, bringing together a wide range of stakeholders to improve the level of preparedness in the UK to major threats and shocks, and the Fundraising Regulator, which oversees charitable fundraising and was established to raise standards and improve public trust in the sector. He is currently undertaking a review of London's preparedness to respond to a terrorist incident, which is a follow up to the review he conducted five years ago.

$\mathrm{He}$ is also the Chair of the Independent Advisory Group on Ethics for the National Crime Agency and the outgoing Chair of National Trading Standards, which delivers national and regional consumer protection enforcement activity.

Angie Heilmann MBE is a registered Dental Nurse who has had a long clinical and academic career. Firstly, in Scotland and then moving to England in 1986. Angie qualified as a Dental Nurse in 1989 and went on to achieve NEBDN qualifications in

Dental Sedation Nursing (with

Distinction) and worked in clinical practice until 2007 before focusing solely on Dental Nurse Tutoring.

Angie has held a number of educational and tutoring positions since then, most recently as the Dental Workforce
Development Regional Advisor for Heath Education England (East) until 2020 and is currently the Director of Dental Nurse Education at Cambridge Dental Nurse Academy, the dental nurse arm of Antwerp Dental Academy. Previously, she was part of the team that introduced Foundation Degrees in Dental Nursing at the University of Bedfordshire.

On the announcement of his appointment, Lord Toby Harris said: 'I am very pleased to be joining the GDC as Chair of Council and look forward to working with my fellow Council Members and the Chief Executive and his senior management team, to ensure that we remain an effective and efficient regulator and that we ensure that public protection is at the heart of everything we do.

'At this time of significant change and after what has been a very difficult period for many dental professionals as a result of the COVID-19 pandemic, I look forward to working collaboratively with colleagues from across the professions to ensure that our approach to regulation is proportionate and focused on the important areas of public safety and ensure public confidence in the professions we regulate.'

Responding to the announcement, BDA Chair Eddie Crouch said: 'We are disappointed that the GDC has again chosen not to select a dentist as Chair. This would have been an important step to rebuild trust with this profession.

'However, a new face offers an opportunity to turn the page. We send our congratulations to Baron Harris and offer our commitment to work with him and his team to secure the costeffective, right-touch regulation dentistry desperately needs.'

\section{Chris Morris elected to BDA Board}

Chris Morris has been elected to the BDA's

Board (known as the Principal Executive

Committee) in the 2021 by-election for the vacant UK-wide seat.

Chris first qualified as a dental surgeon, and practised dentistry in the UK and overseas for ten years before training as a solicitor, becoming a partner at
Hempsons, a national healthcare law firm, where he specialised in defending dentists.

He has served as legal adviser to the British Dental Journal for twenty years, and as President of the Dental Law and Ethics Forum since 2000. His term of office will run until 31 December 2023. 